\title{
On the variation of b-value for Karachi region, Pakistan through Gumbel's extreme distribution method
}

\author{
Naseer Ahmed ${ }^{1} \cdot$ Shahid Ghazi $^{2} \cdot$ Perveiz Khalid $^{2}$ (D)
}

Received: 12 December 2014/ Accepted: 2 June 2015/Published online: 3 July 2015

(C) Akadémiai Kiadó 2015

\begin{abstract}
The accurate estimation of b-value of Gutenberg-Richter (GR) frequencymagnitude relationship is very crucial in seismic hazard analysis of a region. In this study, we focused on the b-value estimated by using Gumbel's extreme distribution and GR methods for Karachi region of Pakistan. The seismotectonic setting of Karachi region is of great significant because it is surrounded by many active faults systems such as Makran subduction, Run of Kutch, Kirthar, Pab fault etc. In the past, low to moderate seismicity has been occurred in Karachi region. However, because of its seismotectonic settings there is the possibility of occurrence of major seismic event. The probability of recurrence of potential earthquake is also investigated in Karachi region. An earthquake catalogue is developed by taking moment magnitude $\left(M_{w}\right)$ as a homogenous magnitude for all events. The completeness of this catalogue is done through taking instrumental data of earthquakes from 1973 onwards. A total of 530 events, occurred in $300 \mathrm{~km}$ surrounding of Karachi city, are selected for analysis of b-value and probability of recurrence. The regression analysis is carried out by GR-relationship to analyze the pattern of earthquake distribution and b-value. The statistical analysis of past earthquakes has computed b-value 0.49 showing inadequate earthquake events. Therefore, to find out b-value for this region with low number of earthquake, lack of data and deficiency of relevant earthquake magnitude, GR methodology is not much appropriate. In this situation, Gumbel's extreme distribution methodology is used, which have shown better results. The regression analysis through Gumbel's method indicates b-value of 0.8 . The probability of recurrence and return periods for different magnitudes is determined by using Gumbel's extreme distribution value approach.
\end{abstract}

Keywords b-value $\cdot$ Karachi $\cdot$ Seismic hazard analysis $\cdot$ Return period

Perveiz Khalid

perveiz.geo@pu.edu.pk

1 Pakistan Nuclear Regulatory Authority (PNRA), Islamabad, Pakistan

2 Institute of Geology, University of the Punjab, Lahore 54590, Pakistan 


\section{Introduction}

The frequency-magnitude relationship plays an important role to understand distribution of earthquake events over a period of time. The regression parameter which is called b-value gives idea of seismicity pattern of the area and stress transferred in the region considering the physical properties of the medium; also it is useful to characterize the seismotectonic behavior of a region (Betbeder-Matibet 2008). The accurate determination of b-value is the fundamental steps in seismicity distribution and seismic hazard analysis of a region (Tinti et al. 1987; Khalid et al. 2014). The well-known empirical relationship between earthquake magnitude $(M)$ and frequency of occurrence of the earthquakes $(N)$ proposed by Gutenberg and Richter (1956) is widely used in earthquake prediction and to find out the rate of exceedence of an event. This relationship is:

$$
\log (N)=a-b M
$$

Here $a$ and $b$ are constant parameters ( $a$ is the measure of level of seismicity in an area and $b$ is generally taken 1). Gutenberg-Richter (GR) approach uses earthquakes of any magnitudes, however, it is noted that this approach works well where large number of seismic events of low to moderate magnitude are available. However, it is found that for earthquakes of low magnitudes the b-value depart from its constant value 1 (Abercrombie 1996). This departure from constant value is attributed by some artifact in recording instruments or earthquake record catalogue.

In this study an analysis is performed to examine the applicability of two statistical approaches which are being used widely. One is Gutenberg and Richter (1956) frequencymagnitude relationship and other is Annual Extreme Values Method of Gumbel's (1958). However, in case of Karachi a composite earthquake catalogue, for instrumental period, from 1973 is developed through USGS, USGS-ANSS and ISC catalogues. In order to improve the accuracy of catalogue a homogenous magnitude scale $M_{w}$ is selected and magnitude conversion is done. Regression of these events based on GR relation yielded $b$-value of 0.49 . This $b$-value is much smaller and indicates inadequacy of earthquake events (Chen et al. 2003).

Karachi is situtated on the Southernmost folds of the Kirthar range (Schelling 1999). Several geological active structures are present near to the city such as Makran subduction, Run of Kutch, Kirthar, Pab fault. Although the city has been safe with respect to any major seismic activity, however some major earthquakes have been occurred around $300 \mathrm{~km}$ of the city (Bilham 2007). The seismotectonic map of Karachi region is shown in Fig. 1.

The main objective of the present study is to get better $b$-value and to determine the probability of reoccurrence of earthquakes in Karachi region of Pakistan. This objective is achieved based on data of instrumental catalogue best available from 1973 onwards. Annual Extreme Values Method of Gumbel (1958) is adapted for Karachi city where larger events are best available because this approach utilizes maximum magnitude (Tezcan 1996; Adnan 2005) of each year and lower the uncertainty due to lack of historic data and relevant magnitudes. Magnitude conversion is done through relationships suggested by Scordilis (2006).

\section{Seismicity of the study area}

Karachi is located very close to the triple junction of Arabian, Indo-Pakistan and Eurassian Plates. Historical and instrumental seismicity indicate different seismotectonic regions such as: Ornach Nal fault, Surjan- Jhimpir faults, Pab fault, Kutch fault etc. Historical 
record shows that in A.D. 893 or 894, the most renowned earthquakes in the Indus delta was from archival sources, which destroyed the town of Debal, or Dvin in Armenia. Oldham (1883) reported that the origin of this earthquake was not in India but in Armenia. In June 1819, a larger earthquake of estimated $M_{w}=7.7 \pm 0.2$ was hutted to Run of Kutch near Lakpat and killed about 1500 people (Baker 1846). A very irregular pattern of earthquakes were reported after this major earthquake during next 50 years. Again an earthquake of $7.1 M_{w}$ occurred along Run of Kutch in January 2001 (Bilham 1998). Historical seismicity of the Karachi region indicates that the city is near to the subduction zone having potential earthquake magnitude $M_{w}=8$ to the west, in the east reverse faulting seismic source with $6<M_{w}<8$ in the Kutch and to the northwest strike rupture of $M_{w} \leq 7.9$. A small data is available to characterize return period and probability of reoccurrence of these events (Byrne et al. 1992; Bilham 2007). Historically, no major seismic event is reported in the Ornach Nal system. Most recently an earthquake of magnitude $7.7 M_{w}$ occurred as the result of oblique-strike-slip type motion at shallow crustal depths. This seismic activity was occurred in the northward collision of the Indian plate with the Eurasia plate and transition zone between northward subduction of the Arabian plate beneath the Eurasia plate. According to USGS, the epicenter of this earthquake is about $69 \mathrm{~km}$ north of Awaran and $270 \mathrm{~km}$ north of Karachi.

\section{Catalogue completeness and magnitude conversions}

Since it is mentioned above that a composite instrumental earthquake catalogue is used in this study and to ensure completeness, period of 1973-2014 is used for $M_{w} \geq 4.8$ (Fig. 2). Total 530 events recorded within the area of about $300 \mathrm{~km}$ of Karachi city are used, although the number of events are smaller but study is restricted to distance range of $300 \mathrm{~km}$ which is widely acceptable range for seismic hazard analysis as earthquake beyond

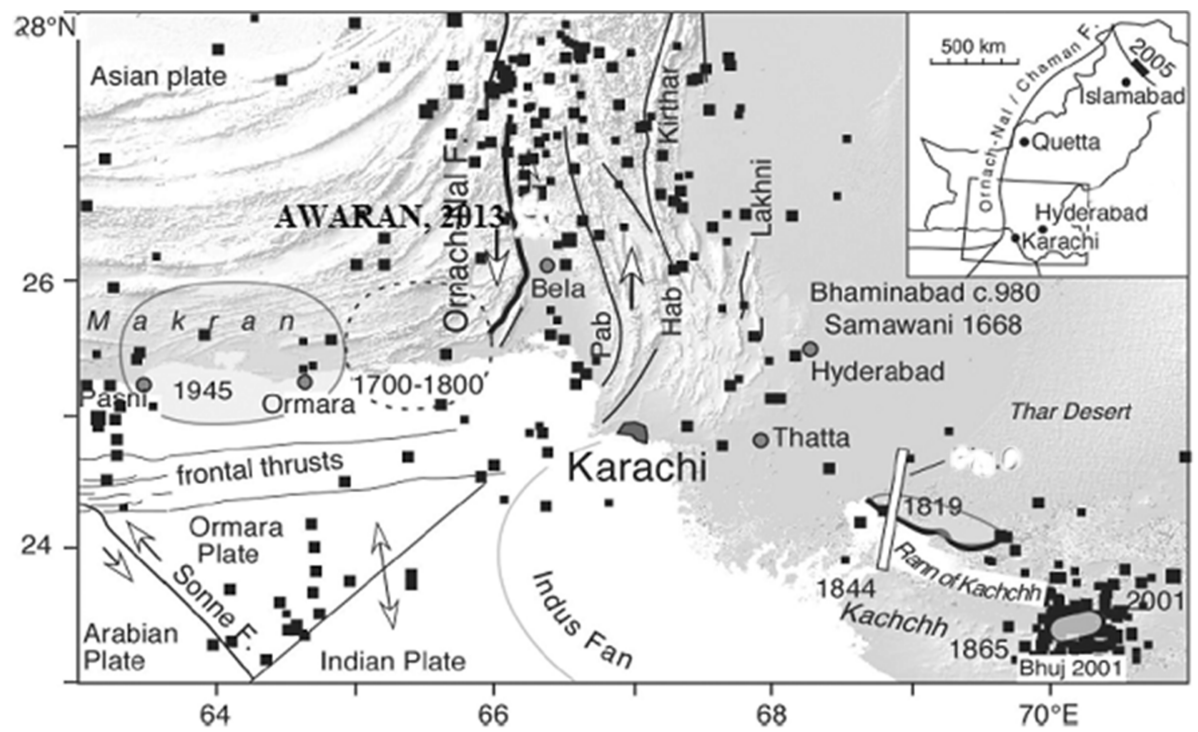

Fig. 1 Seismotectonic map of Karachi (after Bilham 2007) 


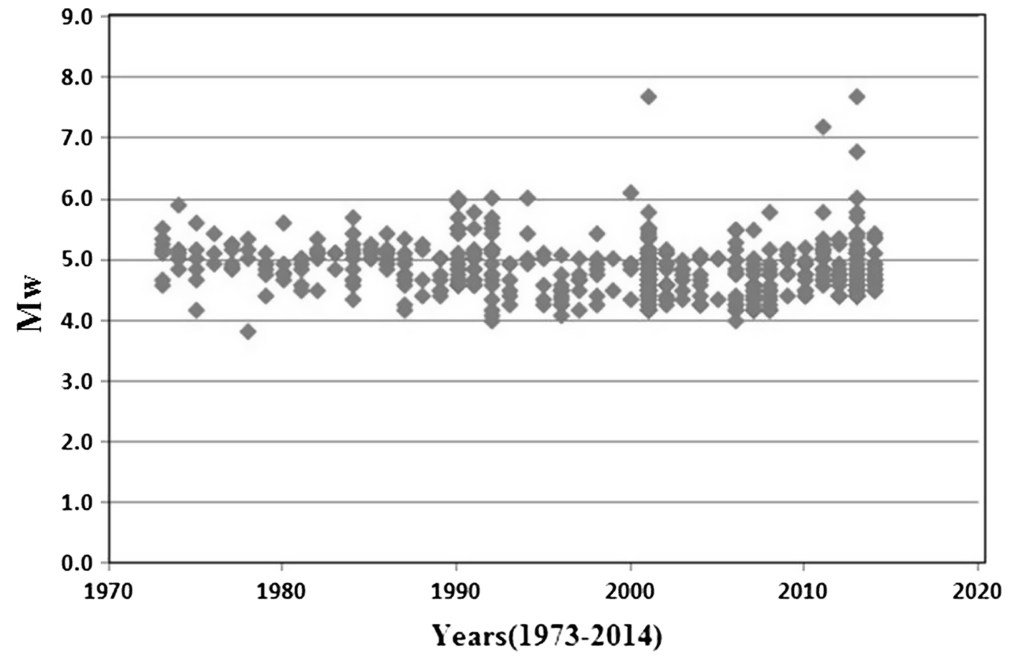

Fig. 2 Distribution of earthquakes of maximum magnitude during time interval (1973-2014) in Karachi region, Pakistan

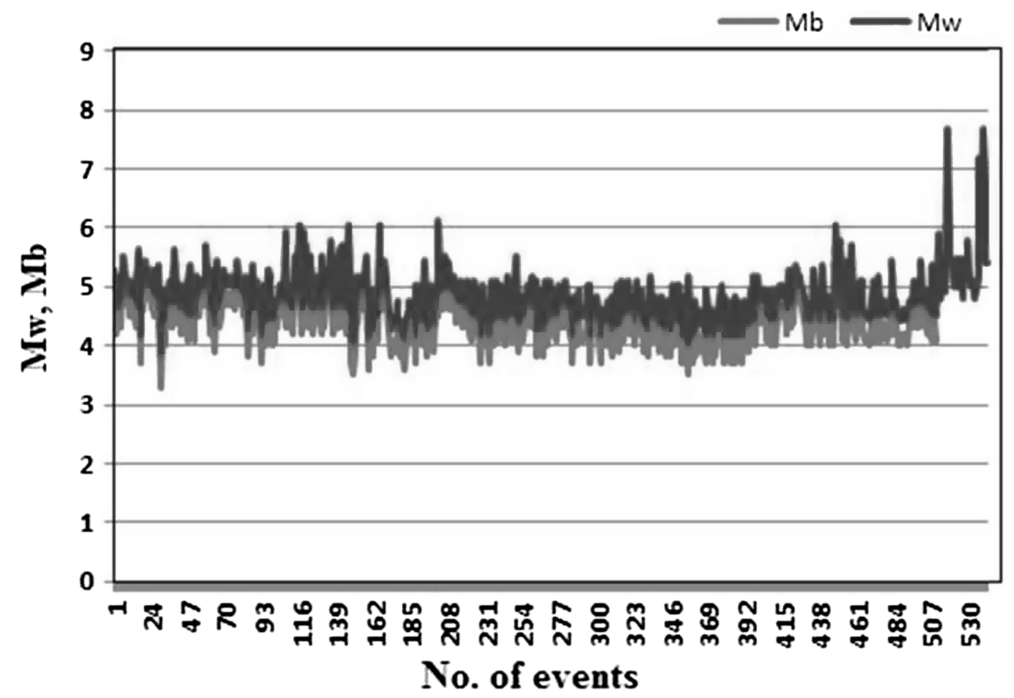

Fig. 3 Conversion of body wave magnitude $\left(M_{b}\right)$ and moment magnitude $\left(M_{w}\right)$ from USGS-ANSS catalogue for study area

this range even it is large in magnitude usually do not damage significantly due to variation of medium and distance from source to site. The processing of earthquake catalogue is done through removal of duplicates, foreshocks and aftershocks. To get a homogenous magnitude $M_{w}$ magnitude conversion is done through relationships given by Scordilis (2006): 


$$
M_{w}=0.85 M_{b}+1.03 ; 3.5 \leq M_{b} \leq 6.2
$$

where $M_{b}$ is the body wave magnitude. It is important to note that the Scordilis relations for $M_{b}-M_{w}$ conversion is valid only for magnitudes up to $M_{b}=6.2$ which is quite evident from Fig. 3, where body wave magnitude and moment magnitude $\left(M_{w}\right)$ of all recorded events are plotted. A close agreement between both magnitudes exists for all events except few events. The magnitude conversion is done through following scheme. First priority was given to $M_{w}$ which was originally reported, secondly $M_{b}$ was converted to $M_{w}$ whenever available and thirdly surface wave magnitude $\left(M_{S}\right)$ was converted to $M_{w}$ whenever available. Since in the catalogue, no surface wave data was available, therefore, only body wave magnitude and $M_{w}$ used in this study.

\section{Calculation of b-value}

To compute $b$-value for Karachi region GR frequency-magnitude relationship and Gumbel's Annual Extreme Values method are used.

\section{1 b-value by GR-relationship}

GR relation (Eq. 1) is used to get the values of regression parameters $a$ and $b$. It is very important to mention that $b$-value of 1 is widely established for zones of low to moderate and high seismicity with sufficient number of events. However, as seen in this case that total number of seismic events 530 is available instrumentally since 1973 onwards. The regression analysis as shown in Fig. 4 tells us inadequacy of historic data and deficiency of relevant magnitudes. However, following GR relation is established which is suggested not suitable for hazard analysis in this case.

$$
\log (N)=1.9565-0.4883 M_{w}
$$

The b-value of 0.49 is found through the instrumental catalogs, however at the same time it is recognized to be lower than the expected value. We do accept this, because removal of foreshocks and aftershocks is done which actually has decreased the numbers of

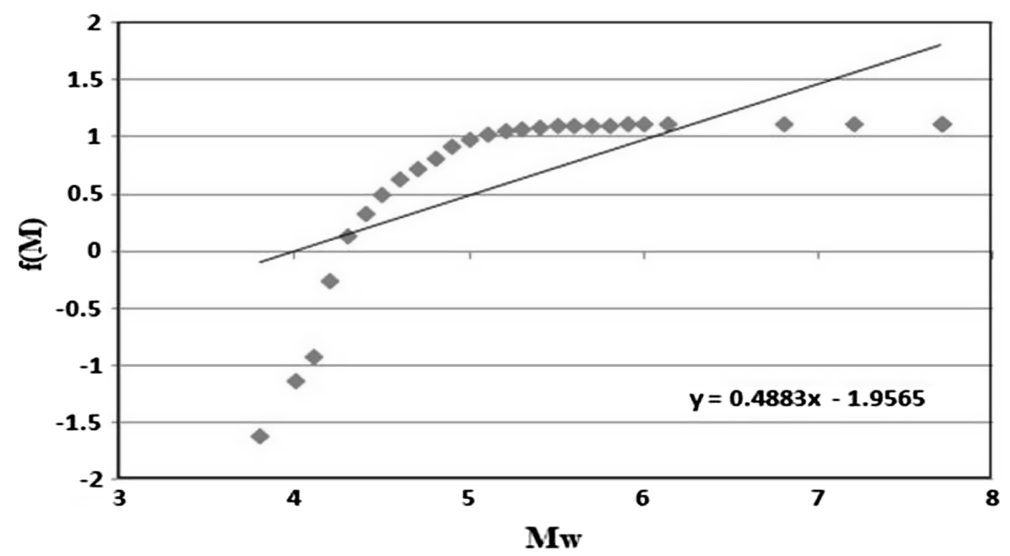

Fig. 4 Earthquake frequency — magnitude relationship for Karachi region 
events as a whole. Although it was realized that possible inclusion of aftershocks could have increased the number of earthquakes but to minimize the uncertainty in catalogue only main events are selected. However, if we use all events then $b$-value may increase towards 1 due to increase in earthquake events which is not used in this case.

\subsection{Application of Gumbel's Annual Extreme Values Method for b-value of Karachi city}

The methodology is used to estimate the magnitudes of future earthquakes based on statistical technique developed by Gumbel's Annual Extreme Values Method (Tezcan 1996) for Karachi city. The probability of not exceeding the earthquake having magnitude more than $\mathrm{M}$ in 1 year is given by

$$
G(M)=e^{-\alpha e-\beta M}
$$

where $M$ is magnitude of earthquake, $\alpha, \beta$ are regression coefficients and $G(M)$ is the probability of not exceeding the earthquakes having magnitudes more than $M$ in 1 year. Following correlations between Gumbel's and GR formulations exists (Tezcan 1996):

$$
\begin{gathered}
\alpha=10^{a} \text { and } \beta=b / \log e \\
N=\alpha e^{-\beta M}
\end{gathered}
$$

The regression constants found by selecting maximum earthquake of the year from 1973 to 2014 from different catalogs given by USGS, ISC are given in Table 1. Finally the values of $a$ and $b$ computed by using least square method based on Eq. (5a) are plotted in Fig. 5. The value of $a$ is 3.7 and of $b$ is 0.8 whereas Gumbel's regressions coefficients ( $\alpha$, $\beta)$ are estimated by using these values of $a$ and $b(\alpha=5011.87, \beta=1.85)$.

Table 1 Calculations of parameters for Gumbel's Annual Maximum Distributions

\begin{tabular}{llllll}
\hline $\mathrm{M}$ & $\mathrm{J}$ & $\mathrm{f}$ & $\mathrm{G}(\mathrm{M})$ & $\mathrm{N}=-\mathrm{LNG}$ & \multicolumn{1}{l}{ LOGN } \\
\hline 4.8 & 1 & 0.024 & 0.024 & 3.729701 & 0.571674 \\
4.9 & 1 & 0.024 & 0.048 & 3.04053 & 0.482949 \\
5 & 7 & 0.167 & 0.214 & 1.539557 & 0.187396 \\
5.1 & 5 & 0.119 & 0.334 & 1.098041 & 0.040619 \\
5.2 & 3 & 0.071 & 0.405 & 0.903986 & -0.04384 \\
5.3 & 3 & 0.071 & 0.476 & 0.741537 & -0.12987 \\
5.4 & 3 & 0.071 & 0.548 & 0.601828 & -0.22053 \\
5.5 & 7 & 0.167 & 0.714 & 0.336206 & -0.4734 \\
5.6 & 2 & 0.048 & 0.762 & 0.271684 & -0.56594 \\
5.7 & 1 & 0.024 & 0.786 & 0.24092 & -0.61813 \\
5.8 & 1 & 0.024 & 0.810 & 0.211074 & -0.67557 \\
5.9 & 1 & 0.024 & 0.834 & 0.182093 & -0.73971 \\
6 & 3 & 0.071 & 0.905 & 0.099873 & -1.00055 \\
6.1 & 1 & 0.024 & 0.929 & 0.073903 & -1.13134 \\
7.2 & 1 & 0.024 & 0.953 & 0.04859 & -1.31345 \\
7.7 & 1 & 0.024 & 0.976 & 0.023902 & -1.62156 \\
\hline & & & & &
\end{tabular}




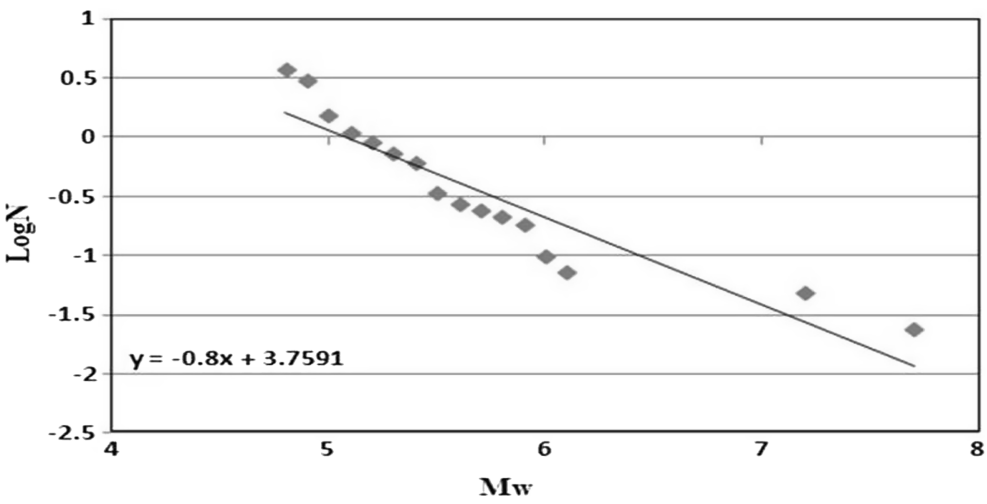

Fig. 5 Crossplot between earthquake magnitude and log of frequency of earthquakes in Karachi region

Table 2 Probabilities of earthquake recurrence for different periods

\begin{tabular}{|c|c|c|c|c|c|c|c|}
\hline$M_{w}$ & $\mathrm{~N}(\mathrm{M})$ & $\mathrm{R} 1$ & $50 \mathrm{~N}$ & R50 & $100 \mathrm{~N}$ & R100 & $T r$ \\
\hline 4.8 & 0.69737 & 0.502 & 34.869 & 1.00 & 69.7372 & 1 & 1.43395 \\
\hline 5 & 0.4817 & 0.382 & 24.085 & 1.00 & 48.1699 & 1 & 2.07598 \\
\hline 5.5 & 0.19101 & 0.174 & 9.550 & 1.00 & 19.1009 & 1 & 5.23536 \\
\hline 6 & 0.07574 & 0.073 & 3.787 & 0.98 & 7.5741 & 0.99949 & 13.2029 \\
\hline 6.5 & 0.03003 & 0.030 & 1.502 & 0.78 & 3.00337 & 0.95038 & 33.2959 \\
\hline 7 & 0.01191 & 0.012 & 0.595 & 0.45 & 1.19093 & 0.69606 & 83.968 \\
\hline 7.5 & 0.00472 & 0.005 & 0.236 & 0.21 & 0.47224 & 0.3764 & 211.756 \\
\hline 8 & 0.00187 & 0.002 & 0.094 & 0.09 & 0.18726 & 0.17077 & 534.021 \\
\hline 8.5 & 0.00074 & 0.001 & 0.037 & 0.04 & 0.07425 & 0.07156 & 1346.73 \\
\hline 9 & 0.00029 & 0.000 & 0.015 & 0.01 & 0.02944 & 0.02901 & 3396.28 \\
\hline
\end{tabular}
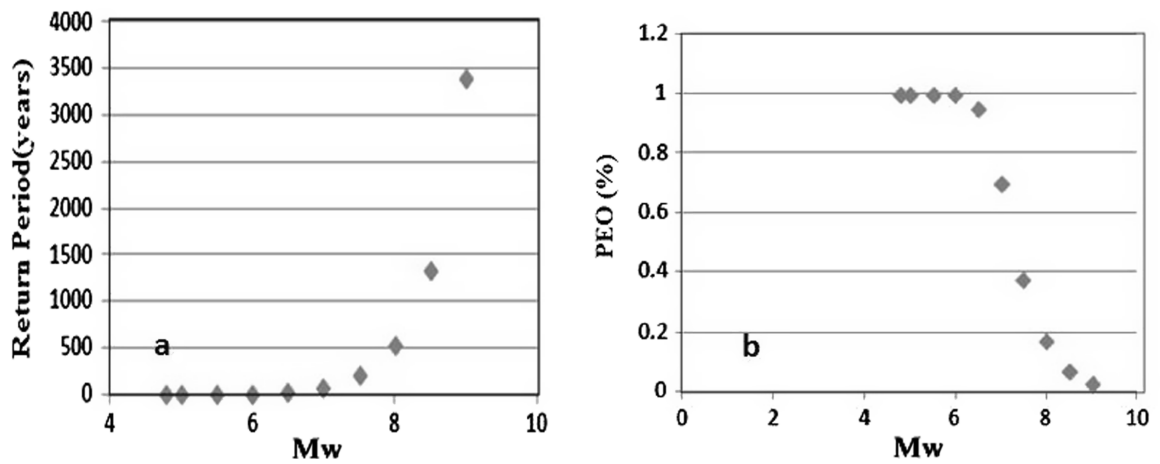

Fig. 6 a Crossplot between $M_{w}$ and return period of the earthquakes of magnitude $M_{w}$, and b Probability of recurrence of earthquake (PEO (\%)) of magnitude $M_{w}$ 


\subsection{Calculation of probability of earthquake occurrence and different return periods}

The probability of recurrence and return period for $M_{w}=4.8-9$ are calculated. The probabilities of earthquake occurrence are calculated for periods of $\mathrm{T}=1,50,100$ years and for magnitude range of $M_{w}=4.8-9$ are presented in Table 2. The probability of an earthquake recurrence $(R)$ of equal or greater than magnitude $=7$ in 100 years is $69 \%$ in this area and its return period $(T r)$ is 83 years. The magnitude and return period and probability of recurrence of each earthquake are cross plotted in Fig. 6. An inverse relation is found between magnitude and return period. Similar relationship exists between magnitude and probability of recurrence of an event.

\section{Conclusions}

Influence of catalogue on $b$-value is analyzed through both GR-relationship and Gumbel's methodology. GR-relation for Karachi region with inadequate earthquake events and lack of historic data may not found suitable with $b$-value of 0.49 . Gumbel's distribution approach found effective for regions like Karachi where large events are available, therefore $b$-value calculated based on this approach is found quite relevant about 0.8 which is used in this study. Gumbel's statistical analysis yielded that the probability of an earthquake occurrence for magnitude 7 is $69 \%, 7.5$ is $37 \%, 8$ is $17 \%$ in 100 years, and return periods are 83, 211, 534 years respectively. Similarly the return periods of other earthquakes with probability of its occurrence is found. In the end it is important to mention that due to complexity of geology and tectonics of the area, and non- availability of adequate historic and instrumental data errors up to 10-15\% may be possible.

\section{References}

Abercrombie RE (1996) The magnitude-frequency distribution earthquakes recorded with deep seismometers at Cajon Pass, Southern California. Tectonophysics 261:1-7

Adnan A, Hendriyawan H, Marto A, Irsyam M (2005) Seismic hazard assessment for peninsular Malaysia using Gumbel distribution method. J Teknol 42:57-73

Baker WE (1846) Remarks on the Allah Bund and on the drainage of the eastern part of the Sind basin. Trans Bombay Geogr Soc 7:186-188

Betbeder-Matibet J (2008) Seismic engineering. John Wiley \& Sons Inc, Hoboken

Bilham R (1998) Slip parameters for the Rann of Kachchh, 16 June 1819 earthquakes, quantified from historical accounts. Geol Soc Lond Spec Publ 146:295-319

Bilham R (2007) Seismic hazard in Karachi, uncertain past, uncertain future. Seismol Res Lett 78(6):601-613

Byrne DE, Sykes LR, Davis DM (1992) Great thrust earthquakes and aseismic slip along the plate boundary of the Makran subduction zone. J Geophys Res 97:449-478

Chen P, Bai T, Li B (2003) The b-value and earthquake occurrence period. Chin J Geophys 46(4):736-749

Gumbel EJ (1958) Statistics of extremes. Columbia University Press, New York

Gutenberg B, Richter CF (1956) Earthquake magnitude, intensity, energy and accelaration. Bull Seismol Soc Am 32(3):163-191

Khalid P, Ghazi S, Yasin Q, Khurrem S (2014) Assessment of seismic hazard of the Kalam-Ashrit Dam, Swat, Pakistan. 3rd Annual international conference on geological and earth sciences (GEOEARTH 2014), Singapore, 22-23 Sept 2104

Oldham TA (1883) Catalogue of Indian earthquakes. Geol Surv India Memoir 19:163-215 
Schelling DD (1999) Frontal structural geometries and detachment tectonics of the northeastern Karachi arc, southern Kirthar range, Pakistan. Geol Soc Am Bull 328:287-302

Scordilis EM (2006) Empirical global relations converting $M_{\mathrm{S}}$ and $m_{\mathrm{b}}$ to moment magnitude. J Seismol $10: 225-236$

Tezcan SS (1996) Probability analysis of earthquake magnitudes. Turkish Earthquake Foundation, Istanbul, p 26

Tinti S, Rimondi R, Mulargia F (1987) On estimating frequency-magnitude relations from heterogeneous catalogs. Pure Appl Geophys 125:1-18 